\title{
COVID-19 presenting as acute pericarditis
}

\author{
Soumitra Ghosh (1) ,' Prashant Panda (1) ,' Yash Paul Sharma, ${ }^{1}$ Neha Handa ${ }^{2}$
}

\begin{abstract}
${ }^{1}$ Cardiology, PGIMER,
Chandigarh, India

${ }^{2}$ Nursing, PGIMER, Chandigarh, India
\end{abstract}

\section{Correspondence to}

Dr Prashant Panda;

prashantpanda85@gmail.com

Accepted 31 December 2021

\section{SUMMARY}

COVID 19, caused by SARS-CoV-2, is a highly infectious

disease, mainly affects the respiratory system. In this article, we have presented a case of COVID-19, who presented solely with pericarditis without myocarditis, without any respiratory symptoms. The diagnosis was made based on clinical, electrocardiographic, radiological and biological findings. He was treated successfully with aspirin and colchicine. Our case highlights an atypical presentation of COVID-19, which should be kept in mind in the present pandemic and to diagnose and isolate early to limit the spread of infection.

\section{BACKGROUND}

COVID-19 19 is a highly infectious disease, transmitted mainly by aerosolised droplet contact, causing an ongoing pandemic. It is caused by SARSCoV-2, an enveloped single-strand RNA virus. ${ }^{1}$ In most people, the disease is mild. Though the respiratory system is most commonly involved in symptomatic patients, it can affect many extrapulmonary systems like cardiac, gastrointestinal, neurological, renal, hepatic, haematological, etc. Cardiovascular manifestations include acute coronary syndrome (ACS) with or without obstructive coronary artery disease, venous thromboembolism, arrhythmias, myocarditis and pericarditis. All these complications may occur in the presence or absence of lung involvement. ${ }^{2}$ Here, we report a case of a 56-year-old COVID-positive man who presented with acute pericarditis (AP) in the absence of lung involvement.

\section{CASE PRESENTATION}

A 56-year-old man presented with acute onset chest pain with an uneasy sensation. Chest pain was initially mild for 1 day but gradually increased in severity for the last 5 hours before presentation. According to the patient, it was a very uneasy sensation over the left side of the chest with radiation to upper limb and shoulder, increasing with exertion, lying flat and deep breath and somewhat relieved by leaning forward. He had no cough, fever or dyspnoea. He was hypertensive, diabetic and a smoker. Family history was significant for coronary artery disease. He had recent travel history to his nearby village. There was no similar case in another family member.

On examination, his heart rate and blood pressure were 86 beats/min and $150 / 86 \mathrm{~mm} \mathrm{Hg}$, respectively, respiratory rate was $22 / \mathrm{min}$, the temperature was 37.4 degree celcius, and an $\mathrm{O} 2$ saturation at room air was 98\%. Cardiovascular system examination revealed normal first and second heart sound with no audible murmur. There was no pericardial rub at the time of examination. Respiratory system examination was also normal.

\section{INVESTIGATIONS}

Considering this clinical scenario in a diabetic middle-aged patient, in whom atypical presentation of ACS is common, working diagnosis of the ACS more than pericarditis was considered. Urgent electrocardiography (ECG) revealed PR depression and ST elevation in the lead II, III, aVF and V1-V6 with PR elevation and ST depression in aVR (figure 1A). $\mathrm{He}$ had normal cardiac biomarkers; creatine kinase was $3.5 \mathrm{ng} / \mathrm{mL}$ (normal: $0-4.3 \mathrm{ng} / \mathrm{mL}$ ), highsensitivity cardiac troponin $\mathrm{T}$ was $<0.05 \mathrm{ng} / \mathrm{mL}$ (normal: $0-0.4 \mathrm{ng} / \mathrm{mL}$ ), brain natriuretic peptide was $27 \mathrm{ng} / \mathrm{mL}$ (normal: 0-100 ng/mL). Even after 5 hours of acute increase of chest pain, normal markers are unusual in ST-Elevation Myocardial Infarction (STEMI). Transthoracic echocardiogram (TTE) confirmed normal systolic and diastolic function, normal valve, although his pericardium was echo bright with no pericardial effusion (PE) (figure 2A,B). Repeat ECG after 1 hour revealed the same finding as to the previous one with no dynamic or progressive ST-T changes (figure 1B). Because of the short duration of symptoms, a nasopharyngeal swab for SARS CoV-2 reverse transcription-polymerase chain reaction (RT-PCR) was sent. Other blood investigations revealed haemoglobin of $0.121 \mathrm{~g} / \mathrm{L}$ total leucocyte count of $11.5 \times 10^{9} / \mathrm{L}$, platelet count of $254 \times 10^{9} / \mathrm{L}, \mathrm{C}$ reactive protein (CRP) of $9 \mathrm{mg} / \mathrm{L}$ (normal $<5 \mathrm{mg} / \mathrm{L}$ ) with normal coagulation profile, and liver and renal function tests. Chest X-ray (CXR) confirmed clear lungs with no abnormality (figure $3 \mathrm{~A}$ ). Repeat cardiac markers after 3 hours again showed normal values. Ruling out ACS, a diagnosis of pericarditis was made based on chest pain, ECG presentation and TTE. With normal markers and normal echo, myocardial involvement was ruled out. In the meantime, SARS CoV-2 RT-PCR turned out to be positive. Pericarditis was considered as COVID-19 related due to pandemic situation and temporal relation with COVID-positivity. A CT of the chest was done to evaluate lung involvement, which was normal with no infiltrates ruling out lung involvement (figure 3B). The patient did not have any clinical features of autoimmunity. Also, autoimmune markers like antinuclear antibody and rheumatoid factor were negative later. The patient did not have any symptoms or signs of tuberculosis or any malignancy. Chest X-ray showed no patch. Sputum examination was not possible as he had no cough. His renal function test and thyroid function test were normal. He had no history of medication prior to this episode. Thus virtually ruling out other 

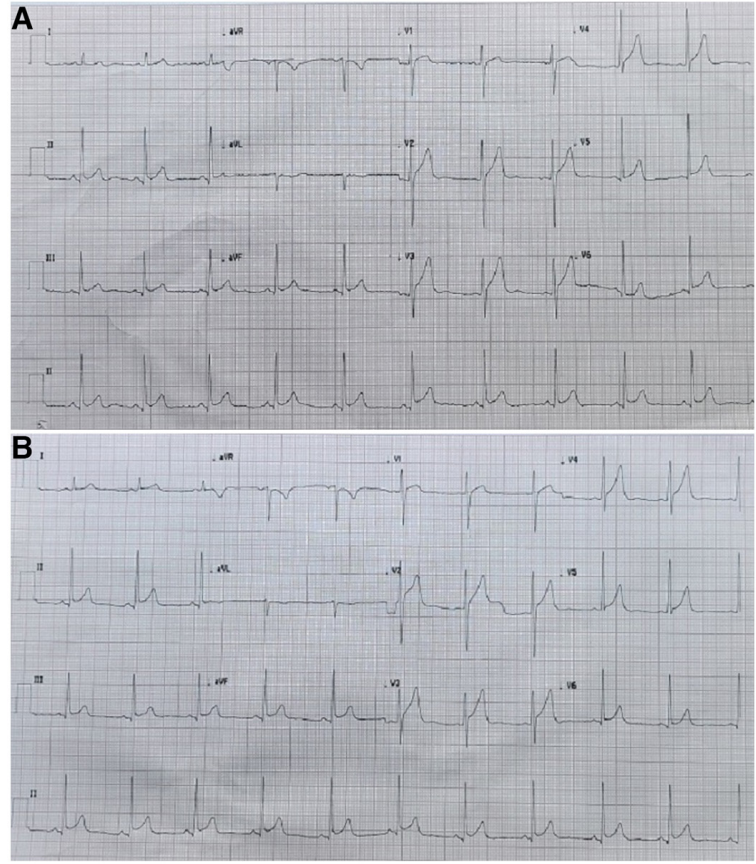

Figure 1 (A) Electrocardiography (ECG) showing PR depression and ST elevation in the lead II, III, aVF and V1-v6 with PR elevation and ST depression in aVR. (B) Repeat ECG after 1 hour revealed the same finding. $\mathrm{aVR}=$ Augmented vector right, $\mathrm{aVL}=$ Augmented vector left, $\mathrm{aVF}=$ Augmented vector foot, PR interval is the time from the beginning of the $\mathrm{P}$ wave (atrial depolarization) to the beginning of the QRS complex (ventricular depolarization), ST segment is an interval between the end of the QRS complex to the beginning of the T wave.

major causes of pericarditis, his pericardial pain was attributed to COVID-19 infection.

\section{TREATMENT}

He was started on high-dose aspirin (650 mg three times a day) with colchicine $(0.5 \mathrm{mg}$ two times a day). He responded dramatically with this treatment. Chest pain rapidly decreased.

\section{OUTCOME AND FOLLOW-UP}

He was discharged in stable condition on day 5 with the advice to complete 2 weeks of treatment and isolate himself at home for 2 weeks. On follow-up after 3 weeks, he was absolutely fine with no chest pain.

\section{DISCUSSION}

Though the respiratory tract is typically involved in COVID19 , it has multiple adverse effects on the cardiovascular system, which is less recognised and described. A rare cardiovascular system (CVS) manifestation of COVID-19 19 is AP with or without myocarditis and with or without lung involvement. ${ }^{2}$ Our patient presented solely with AP without myocarditis in the absence of any respiratory symptoms. There are very few such cases reported in the literature. ${ }^{3}$

The most common disease involving pericardium is AP, which makes $0.2 \%$ of chest pain-related hospitalisations. Viral infections most commonly cause it. ${ }^{4}$ At present, limited data have been published on cases with COVID-19 who develop pericarditis and PE. Most reported cases had been associated with myocardial involvement with troponin elevation. ${ }^{5}$ Chest pain is the main symptom. Pericarditis may or may not cause PE. PE

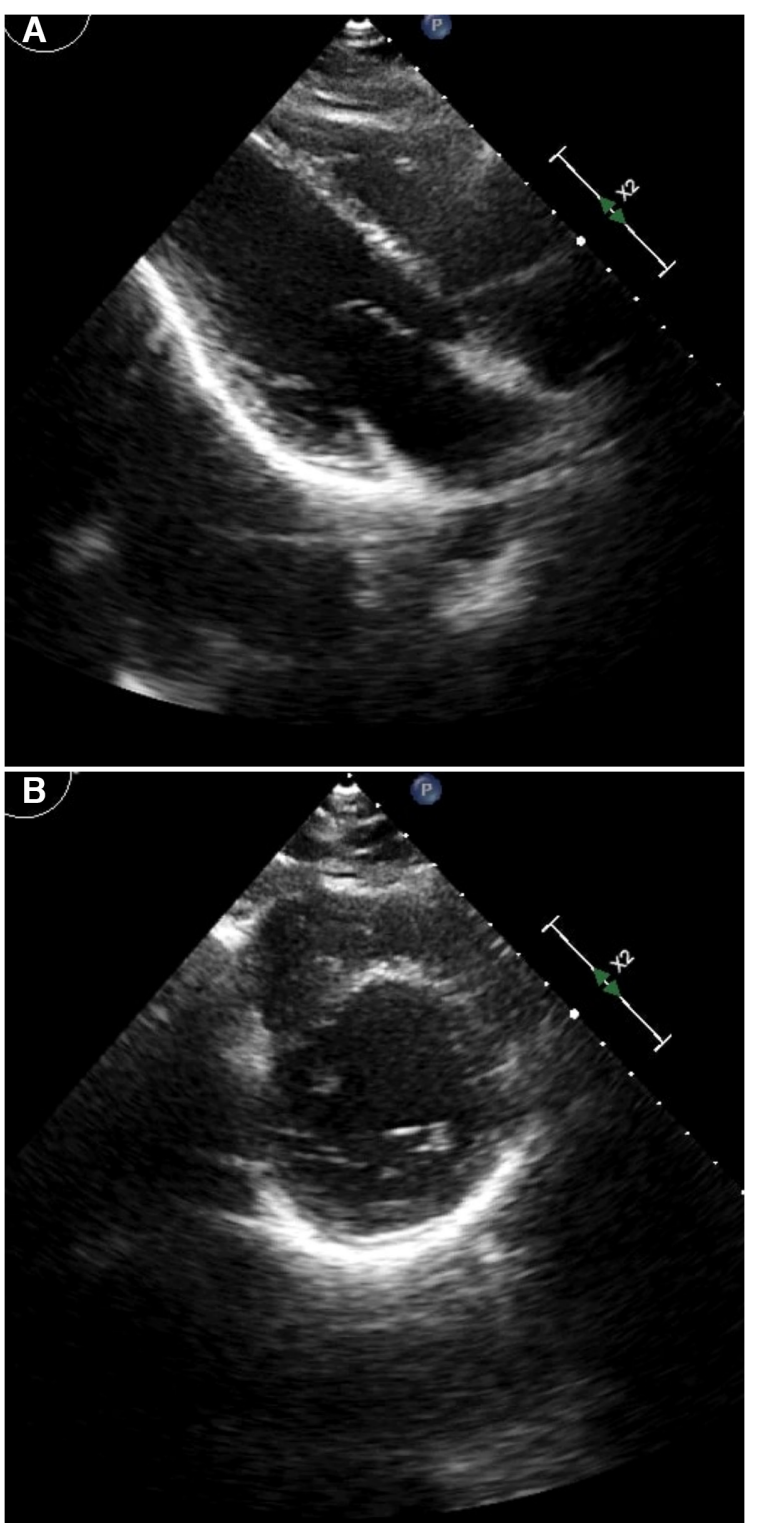

Figure 2 ( $A, B)$ Transthoracic echocardiogram showing echo bright pericardium with no pericardial effusion normal systolic and diastolic function, normal valve.

may be minimal to massive causing cardiac tamponade. Our patient had no PE.

Chest pain in COVID-19 may have cardiac causes, including ACS, pericarditis and myocarditis. Pericarditis is diagnosed if two or more of the following are present: (1) Typical chest pain (sharp and pleuritic, improved by sitting up and leaning forward); (2) Friction rub; (3) Typical ECG finding of widespread ST elevation with PR depression and (4) New or worsening PE. Elevated inflammatory marker is supportive evidence. ${ }^{6}$ TTE is recommended to rule out PE, but pericarditis may occur even without effusion. Contrast-enhanced MRI is the investigation of choice to see pericardial thickening, detect pericardial inflammation on late gadolinium phase and detect small effusions not appreciated on TTE assessment of myocarditis on T2-weighted imaging. Detecting the cause of pericarditis is not always possible. If PE is present, pericardiocentesis and analysis of pericardial fluid is the gold standard. ${ }^{7}$ However, it is avoided; it carries a severe risk of associated cardiac injury. 

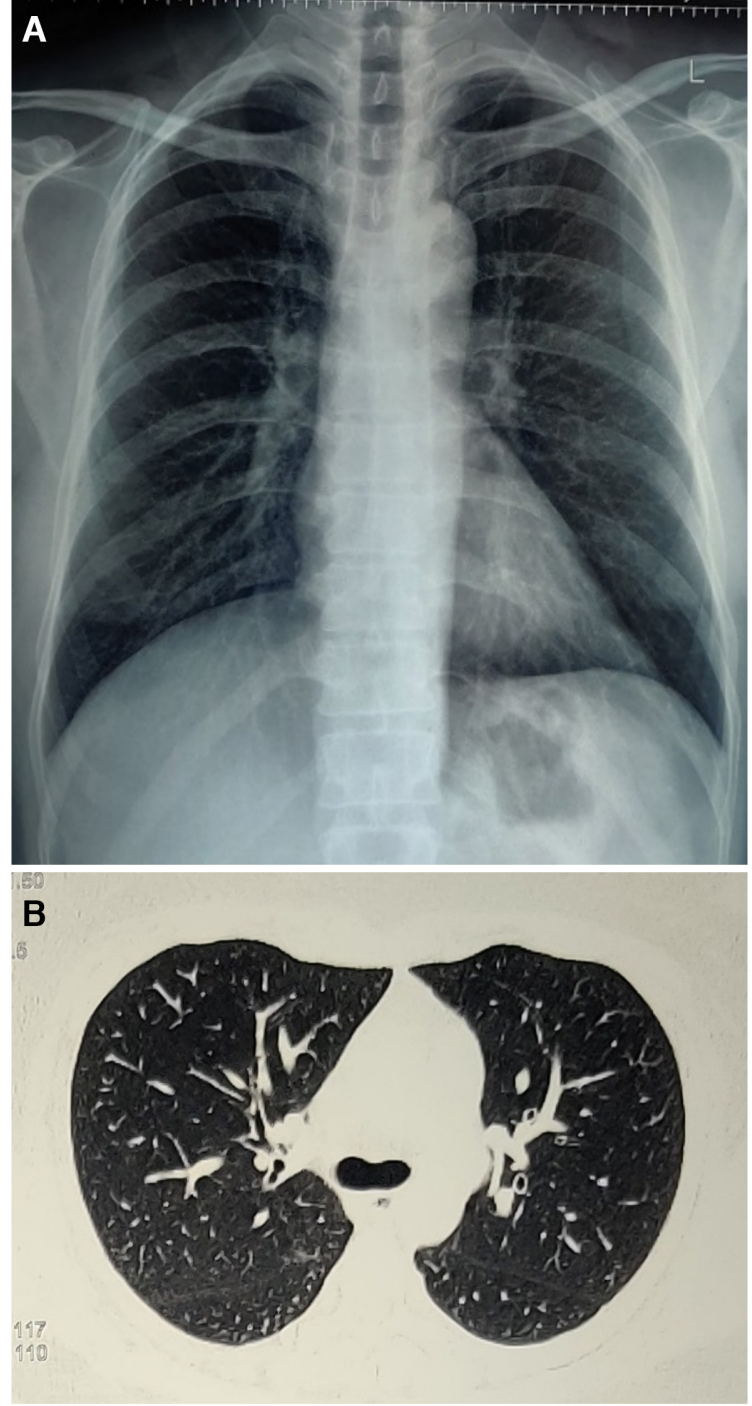

Figure 3 (A) Chest X-ray showing clear lungs with no abnormality and no infiltrate. (B) Representative section of CT of chest showing clear lungs with no infiltrate.

In our patient, we kept the possibility of pericarditis clinically. Considering the risk factors and some 'angina-like symptoms and ST elevation in ECG,' we also kept a differential diagnosis of ACS. However, no dynamic ECG changes, standard biomarkers twice with no systolic dysfunction on echo but made likely pericarditis diagnosis. Increased inflammatory markers thickened, and bright pericardium on echo also supported this. We, unfortunately, could not do an MRI of this patient. In our case, in the absence of pericardial fluid analysis, the association between COVID-19 and idiopathic pericarditis cannot be ruled out. Moreover, temporal correlation with COVID-19 positivity made COVID-19 pericarditis likely.

There are two schools of thought regarding the pathogenesis of COVID-19 pericarditis. One is the direct passage of the virus to the heart. SARS-CoV-2 could pass, via blood or lymphatic system, from the respiratory tract to the heart, including pericardium through binding ACE2 receptors. ${ }^{8}$ RT-PCR has detected it in the pericardial fluid in patients with cardiac tamponade. The other thought is about the systemic immune-inflammatory response to the infection, which causes cytokine release syndrome. It is characterised by a sharp rise of proinflammatory cytokines like IL-6, IL-10, IL-2 and IFN- $\gamma$ in the lungs or in the bloodstream, from which the cardiovascular system is affected. The immune-inflammatory activation correlates well with increased inflammatory markers (CRP first) in myocarditis and pericarditis. ${ }^{89}$

Non-steroidal anti-inflammatory drugs (NSAIDs) are the primary therapy of AP along with colchicines, corticosteroids being the second option. ${ }^{10}$ Despite some warnings about the aggravation of disease by NSAIDs, there is no strong evidence supporting this against its use. ${ }^{11}$ NSAIDs should be the treatment of choice unless they are contraindicated. Colchicine, on the other hand, inhibits microtubule and inflammasome activity, thus having anti-inflammatory activity. It also prevents the relapse of AP. It may modulate immune-inflammatory response to SARS-CoV-2 infection also. ${ }^{12}$ Recent GRECCO-19 trial (The GReek Study in the Effects of Colchicine in Covid-19) showed that participants who received colchicine had statistically significantly improved time to clinical deterioration compared with a control group that did not receive colchicines. ${ }^{13}$ COLCORONA trial (Colchicine Coronavirus SARS-CoV2 Trial) concluded that among patients with PCR-confirmed COVID-19, colchicine led to a lower rate of the composite of death or hospital admission than placebo. ${ }^{14}$ An open-level RECOVERY (Randomised Evaluation of COVID-19 Therapy) Trial showed no difference of all-cause mortality, the median time to being discharged alive, discharge from the hospital within 28 days, and receipt of invasive mechanical ventilation or death between colchicines and placebo. ${ }^{15}$ The most recent National Institutes of Health (NIH) guideline recommends against the use of colchicine to treat hospitalised patients with COVID-19. ${ }^{16}$ Other agents that have been tried with the doubtful role are azathioprine, anakinra and IVIg. ${ }^{10} 11$

Steroids can be used if NSAIDs are contraindicated, or there is concomitant ARDS. ${ }^{11}{ }^{17}$ However, careful monitoring of possible superimposed bacterial infections is warranted when corticosteroids are used. There is also a concern that steroids can increase the risk of recurrent pericarditis. ${ }^{11}$ We treated our patient with high-dose aspirin and colchicines, and he responded well to this treatment.

Recently, with the widespread use of the COVID-19 vaccine, reports of vaccine-related pericarditis are coming up, though they are mild and resolve within a few days to a few weeks. ${ }^{18} 19$

\section{CONCLUSIONS}

Our case illustrates that only pericarditis may be the sole manifestation of COVID-19 without myocarditis or lung involvement. Every clinician should be aware of it. Recognising such presentation is essential to start treatment promptly and isolate the patient to prevent the spread of the disease.

\section{Learning points}

- COVID-19 may present with pericarditis without myocarditis or respiratory symptoms.

- This atypical presentation should be recognised for early isolation and limitation of the spread of the disease.

- Aspirin with colchicine is effective in the treatment of COVID-19 pericarditis.

- COVID-19 vaccine may be associated with mild and selflimiting pericarditis.

Twitter Soumitra Ghosh @DrSoumitraGhos1 
Contributors SG: drafting the article, analysis and interpretation. NH: drafting the article and manuscript preparation. PP and YPS: drafting the article and revising its intellectual content.

Funding The authors have not declared a specific grant for this research from any funding agency in the public, commercial or not-for-profit sectors.

Competing interests None declared.

Patient consent for publication Consent obtained directly from patient(s)

Provenance and peer review Not commissioned; externally peer reviewed.

Case reports provide a valuable learning resource for the scientific community and can indicate areas of interest for future research. They should not be used in isolation to guide treatment choices or public health policy.

\section{ORCID iDs}

Soumitra Ghosh http://orcid.org/0000-0001-6441-645X

Prashant Panda http://orcid.org/0000-0002-2420-5209

\section{REFERENCES}

1 Zhu N, Zhang D, Wang W. China novel coronavirus investigating and research team. A novel coronavirus from patients with pneumonia in China, 2019. N Eng/ J Med 2020;382:727-33.

2 Inciardi RM, Lupi L, Zaccone G, et al. Cardiac involvement in a patient with coronavirus disease 2019 (COVID-19). JAMA Cardiol 2020;5:819-24.

3 Kumar R, Kumar J, Daly C, et al. Acute pericarditis as a primary presentation of COVID-19.. BMJ Case Rep 2020;13:e237617.

4 Kytö V, Sipilä J, Rautava P. Clinical profile and influences on outcomes in patients hospitalized for acute pericarditis. Circulation 2014;130:1601-6.

5 Shafi AMA, Shaikh SA, Shirke MM, et al. Cardiac manifestations in COVID-19 patients-A systematic review. J Card Surg 2020;35:1988-2008.

6 Gabrielli M, de Cunzo T, Bungaro MC. Covid-19 and acute pericarditis: a case report and review of the literature. J Bacteriol Mycol 2020;7:1145.
7 Koos R, Schröder J, Kühl HP. Acute viral pericarditis without typical electrocardiographic changes assessed by cardiac magnetic resonance imaging. Eur Heart J 2009;30:2844.

8 Lin L, Lu L, Cao W, et al. Hypothesis for potential pathogenesis of SARS-CoV-2 infection-a review of immune changes in patients with viral pneumonia. Emerg Microbes Infect 2020;9:727-32.

9 Hendren NS, Drazner MH, Bozkurt B, et al. Description and proposed management of the acute COVID-19 cardiovascular syndrome. Circulation 2020;141:1903-14.

10 Imazio M, Adler Y. Treatment with aspirin, NSAID, corticosteroids, and colchicine in acute and recurrent pericarditis. Heart Fail Rev 2013:18:355-60.

11 Imazio M, Brucato A, Lazaros G, et al. Anti-Inflammatory therapies for pericardial diseases in the COVID-19 pandemic: safety and potentiality. J Cardiovasc Med 2020;21:625-9.

12 Bayes-Genis A, Adler Y, de Luna AB, et al. Colchicine in pericarditis. Eur Heart J 2017;38:1706-9

13 Deftereos SG, Giannopoulos G, Vrachatis DA, et al. Effect of colchicine vs standard care on cardiac and inflammatory biomarkers and clinical outcomes in patients hospitalized with coronavirus disease 2019: the GRECCO-19 randomized clinical trial. JAMA Netw Open 2020;3:e2013136.

14 Tardif J-C, Bouabdallaoui N, L'Allier PL, et al. Colchicine for community-treated patients with COVID-19 (COLCORONA): a phase 3, randomised, double-blinded, adaptive, placebo-controlled, multicentre trial. Lancet Respir Med 2021:9:924-32.

15 RECOVERY Collaborative Group. Colchicine in patients admitted to hospital with COVID-19 (recovery): a randomised, controlled, open-label, platform trial. Lancet Respir Med 2021;9:1419-26.

16 Colchicine, 2021. Available: https://www.covid19treatmentguidelines.nih.gov/ therapies/immunomodulators/colchicine

17 Furqan MM, Verma BR, Cremer PC, et al. Pericardial diseases in COVID19: a contemporary review. Curr Cardiol Rep 2021;23:90.

18 Das BB, Moskowitz WB, Taylor MB, et al. Myocarditis and pericarditis following mRNA COVID-19 vaccination: what do we know so far? Children 2021;8:607.

19 Hudson B, Mantooth R, DeLaney M. Myocarditis and pericarditis after vaccination for COVID-19. J Am Coll Emerg Physicians Open 2021;2:e12498.

Copyright 2022 BMJ Publishing Group. All rights reserved. For permission to reuse any of this content visit

https://www.bmj.com/company/products-services/rights-and-licensing/permissions/

BMJ Case Report Fellows may re-use this article for personal use and teaching without any further permission.

Become a Fellow of BMJ Case Reports today and you can

- Submit as many cases as you like

- Enjoy fast sympathetic peer review and rapid publication of accepted articles

- Access all the published articles

- Re-use any of the published material for personal use and teaching without further permission

\section{Customer Service}

If you have any further queries about your subscription, please contact our customer services team on +44 (0) 2071111105 or via email at support@bmj.com.

Visit casereports.bmj.com for more articles like this and to become a Fellow 